believed that she had early (early-not mild) acute appendicitis. What, then, is the cause of her abdominal pain? It is much more difficult to answer this question than to say that she has not got appendicitis. Stabbing pain in the right iliac fossa suggests caecal spasm and, if she is thin, the contracted caecum or ascending colon may be palpable and tender. Pain from an ovary is not very likely unless it occurs consistently midway between periods, although it is strange that this syndrome is so much commoner in young women than in young men. Crohn's disease is just a possibility but very unlikely if she is physically well and has normal bowel habits, and it would probably not be very rewarding to do barium studies. If extensive investigation seems called for it would have to include intravenous pyelography, but central abdominal pain hardly makes one think of a renal origin and she surely is not suffering from two painful disorders. It really seems as if we are left with the old choice between waiting or looking to see.
My own bet is that she will have her appendix removed and never thereafter trouble her doctor again.

\section{Postscript to the problem}

Eighteen months have passed since this issue was raised. The girl has indeed had a normal appendix removed but continues to consult more often than most girls of her age-now with irregular diarrhoea and vomiting. The clinical picture is fairly certainly that of the irritable bowel syndrome, although this has been diagnosed without referral for exclusion of other disease. She has declined contraceptive advice but, since the most lengthy and frank discussion of her emotional problems, has consulted four separate doctors in the practice once each, two of them being successive trainees. We have not seen her mother since the appendix operation.

\title{
Letter from . . . Chicago
}

\section{Return of the hangman}

\author{
GEORGE DUNEA
}

British Medical fournal, 1977, 1, 1069-1070

The hangman returned to America this winter after an absence of nearly 10 years, but only figuratively speaking: for the condemned man was not hung by the neck but strapped into a chair and shot at sunrise. A murderer of two innocent men, he had achieved widespread publicity by choosing to die rather than live out his days in prison, and by being duly resuscitated from a hunger strike and two suicide attempts so that he could be properly executed. Interminable appeals and legal entanglements delayed the execution and heightened the suspense. But at last a squad of five gunmen administered the death rites, the men having been selected from a much larger group of all too eager volunteers. Five guests only were invited to the ceremony. The gunmen hid discreetly behind a parapet, their rifles only sticking out through holes in the canvas. Problems of conscience were avoided by issuing a blank cartridge to one of the men. Even the television cameras were excluded from the affair. And since the reporters were not allowed to rush into the room to examine the four bullet holes in the back of the chair until the body was removed, the public had to be satisfied with sketches of the scene and pictures of the empty chair.

Pious opponents of capital punishment called the episode a barbaric, degrading, and morbidly disgusting spectacle. Some argued that executions, far from being a deterrent, may actually incite people to acts of violence; that capital punishment is discriminatory since more poor people and ethnic minorities end up on death row; and that innocent men may mistakenly be condemned and executed. Yet, with the crime rate soaring to unprecendented heights, and with violence against strangers by far exceeding crimes of passion, the polls show that some $65^{\circ}$ o of Americans now favour the death penalty. In this they are supported by the analysis of an Illinois university professor who estimates that every execution will prevent some 150 murders. And the mood is reflected by the legislator who proclaimed that the time has come to"strike fear into the hearts of the mad dogs who have declared war on society."

The death penalty had not been invoked in the United States since 1967, when Luis Monge was put to death in Colorado's gas chamber for murdering his wife and three of his 10 children. In 1972 a liberal US Supreme Court ruled that death penalty statutes, as applied by most States, were unconstitutional because they placed too much discretion in the hands of juries and judges. In 1976, however, a more conservative court decided by a majority of seven to two that the death penalty was not an inherently cruel and unusual punishment, provided that the States observed certain guidelines and allowed judges and juries to take into consideration mitigating and aggravating circumstances. As a result of this ruling several States are now revising their penal codes to allow capital punishment for particularly heinous crimes. Some 600 condemned men and women are presently waiting on death row throughout the country, and many are likely to be executed as opportunities for appeal are exhausted. Only time will tell whether such extreme measures will stem the rising tide of violence in our society. Meanwhile, it is unfortunate that the more civilised and probably more effective measure of banning handguns still remains in abeyance.

\section{Public drunks}

By contrast, however, society is adopting a more civilised approach towards the public drunk; and in July 1976 Illinois 
became the 26th state to recognise inebriation as a sickness rather than a crime. Under the 1976 Act public drunks "may not be subjected to criminal prosecution solely because of their consumption of alcoholic beverages but rather should be afforded a continuum of treatment in order that they may lead normal lives as productive members of society." People incapacitated by alcohol who are a danger to themselves or to others will be taken into protective custody and transported to the nearest hospital or detoxification centre. Less severely intoxicated persons who consent to assistance will be helped home or to a public or private facility, but will not be arrested. There are provisions for setting up detoxification centres, generally staffed by paramedical personnel and linked to hospitals that will accept referrals on a no-decline basis

Although all the 26 State laws are based on a uniform federal model and embody enough features to qualify the States for federal funds, considerable regional differences prevail. Some States mandate that the counties set up treatment centres; others leave the responsibility to the State. In Wisconsin, the centres are staffed by doctors; in Illinois by paramedics, according to the Toronto model. In some States the policeman provides the means of entry into the treatment system; in others any person may take a drunk into custody.

In Illinois complete chaos marked the first days of the new law because the legislators had set the opening of the detoxification centres three months after the date of implementation of the law. Police swamped hospital casualty departments with hordes of drunks; so that the governor had to call a special session of the legislature to authorise the immediate opening of the detoxification centres and amend the provision in the law requiring drunks to be first examined by a medical practitioner. But at present the new system works well; three centres are now open in Chicago and soon there will be seven, with a total of 30 for the entire State. Most drunks are shipped directly to detoxification centres instead of the old police "drunk tank;" less than $3 \%$ are taken to hospitals; and police arrests are made only for disorderly conduct.

\section{Coroner's office}

Another recent legislative change in Chicago was a final inquest into the coroner's office. Dating back to the reign of Henry I and at first reserved to "none but lawful and discreet knights," the coroner's office formerly concerned itself with such problems as outlawry, sanctuary laws, repudiation of oaths, contraband, and jurisdiction over treasure trove. Transplanted to Chicago in 1831, the office remained elective and, in theory, powerful, the coroner being the only person who could arrest the sheriff. In practice, however, his duties became limited to determining the cause of death when circumstances were suspicious, obscure, or mysterious.

The system had been under criticism for decades. Most coroners were not doctors, and had neither expert knowledge nor adequate facilities. Necropsies were often done inadequately, and the evidence was often improperly evaluated. In fact, the history of coroner's inquests in the United States abounds with extraordinarily incompetent verdicts: battered babies signed out as crib deaths or "acute capillary fibrosis"; rulings of aspirin overdose at blood salicylate concentrations of $1.2 \mathrm{mg}$ / $100 \mathrm{ml}$; deaths from aerosol sniffing or criminal abortion signed out as myocarditis; and bodies with multiple stab wounds released to funeral homes without further investigations. In one case of suspected drug overdose the blood was placed in a container contaminated with embalming fluid so that barbituate concentration could not be determined; and in another a subsequent examination of the exhumed body showed that the stomach had never been opened. A man who broke his neck while jumping from a bridge on to a frozen river was signed out as drowned. A pilot in a much publicised aircrash was mistakenly declared to have had a heart attack. And in the investigation of the killings of the leaders of the Black Panthers by the Chicago police, the wounds were inadequately described, much evidence was lost, the entrance and exit bullet holes were reversed, and the overall evidence was so conflicting that the truth may never be known.

In Chicago, during its 145-year history, the coroner's office has been held by 33 men-only three of them doctors. Many of the earlier coroners were flamboyant political wildmen, with gaudy clothes and big cigars, whose eccentricity and incompetence had become legendary. Fond of publicity, they would often rush to the scene of crimes to pose for photographs, perhaps holding up the victim's hat or head, or pointing at the fatal wound with their cigar. There were stories of fixed investigations; kickback schemes; and collusion with the underworld, the politicians, and the funeral home directors; and during the prohibition many a gangstyle execution was wound up with the verdict of death from accidental or undetermined causes.

In his work the coroner was helped by a small band of deputy coroners, individuals of limited education who had obtained their training on the job, who had been "active politically," and who had developed expertise mainly in appraising jewellery. Inquests were held at the county morgue, with the jury, mean age 70 , quietly dozing along in what had become a prized sinecure for veteran political precinct captains and patronage workers. Most cases were settled within seven to 15 minutes, and the verdict was often predetermined but had no legal standing; yet the coroner's office provided 85 political patronage jobs and was a great convenience to politicians, the police, and the undertakers.

Attempts to change the system in Chicago had floundered for decades. Meanwhile 36 other states had established at least partial medical examiner's systems. But in 1972 the people of Cook County voted by a majority of six to one to abolish the elective coroners' office and replace it by a medical examiner system. After the election an ordinance was written requiring the appointment of an academically based doctor with degrees in pathological anatomy and forensic pathology. The first medical examiner, a full professor at one of Chicago's medical schools, took office on 6 December 1976, with the county morgue becoming the Morris Fishbein Institute of Forensic Medicine. A team of scientists, consultants, and investigators were recruited, and advanced laboratories were set up. For the time being the emphasis must remain on traditional pathology. But, with less than $10^{\circ}{ }_{0}$ of referred deaths being homicides, the new medical examiner looks forward to an expanded role, which would include problems of the environment, rape, sudden infant death, child abuse, accidents, suicides, paternity cases, and the provision of organs for transplantation-an important office and one clearly requiring "none but lawful and discreet knights."

Are androgens likely to help a 75-year-old man who has recently become impotent? He is healthy and previously led an active sexual life.

This patient sounds as though he is the "eternal optimist." I doubt very much whether androgens will help at all, though there is no harm in trying a short course of, say, three weeks. I think he should be told to accept the fact that all good things come to an end, and he should be congratulated on being so successful for so long.

Are folate supplements usually needed for patients who have had a partial gastrectomy?

Regular folate supplements are not usually needed after partial gastrectomy. Folate deficiency does occur but it is rare, and may well be associated with other evidence of malabsorption. Stammers and Williams ${ }^{1}$ suggest that chronic iron deficiency may in some way lead to folic acid depletion.

' Stammers, F A R, and Williams, J A, Partial Gastrectomy. London, Butterworths, 1963. 